\title{
THE PROBLEM OF CHRONIC RHEUMATISM.
}

\author{
By CHARLES W. BUCKLEY, M.D., F.R.C.P. \\ (Physician to the Devonshire Royal Hospital, Buxton, and to the \\ Buxton Clinic for Rheumatic Diseases.)
}

Possibly no subject has received more attention in medical literature during the past few years than chronic rheumatism, without, it must be admitted, bringing much addition to our knowledge of the ætiology and pathology of the diseases which are grouped under this title. Many observations have been published and conclusions drawn therefrom only to be riddled with destructive criticism by other workers till the fog seems denser than ever.

We know a good deal as to the predisposing causes of rheumatic disease but little as to how those causes exert their effect and the immediate cause seems " not proven." Thanks to the work of Strangeways and Fisher in this country, and of Nichols and Richardson, Allison and Ghormley in America, the naked eye and microscopical appearances of rheumatoid and osteo-arthritis have been thoroughly investigated but without throwing much light on the ætiology or furnishing more than a general basis of classification, and even in this respect, or at least in the matter of nomenclature, there is a marked lack of unanimity.

The American physician who compared rheumatic diseases with the spectrum with its well defined colours shading off gradually into each other furnished an apt picture of the problem.

A few years ago there was a general disposition to believe that the cause of rheumatoid arthritis was a streptococcus derived from some septic focus in the body, and when one reflects upon the thousands of healthy teeth which have been sacrificed to this idea the memory of the ivory gate described in the Æneid, through which false dreams are sent to plague mankind, comes back to mind in an association probably not dreamed of by the poet.

It must nevertheless be admitted that a considerable number of instances have been recorded of complete recovery from arthritis of the infective type following removal of septic teeth, tonsils or appendices which establishes the fact that such foci may play an important part in the ætiology of the disease.

Possibly much confusion and many conflicting findings as to the type of microbe responsible may be traced to a lack of exactitude in diagnosis, for it must be obvious to anyone of experience that morbid conditions presenting marked differences clinically have been grouped together under the generally accepted class designation - rheumatoid arthritis. Some would make a distinction between what they term "true" rheumatoid arthritis, a poly-articular symmetrical form primarily affecting the small joints of the hands and in which they fail to find any focus of infection, and infective or focal arthritis, which is characterized by obvious septic foci, with a less definite mode of attack and affecting only a few joints and those not at first symmetrical. The difference may be essential but the types shade into one another and it is difficult to accept the argument that because no obvious focus can be found, none exists; there are too many possibilities of hidden foci such as the appendix, the gall bladder, the Fallopian tubes and the prostate. Nor is the distinction which has been based on radiological appearances any more certain, and the question of whether osteoporosis affects only the articular ends of the bones entering into the affected joints, or extends to the whole skeleton, appears to many to be mainly a difference depending upon the severity of the infection or the general constitutional state of the patient. After all, the most extreme osteoporosis is met with in senile disease. 
Nevertheless, if a research into the bacteriology of arthritis were sharply limited to a group of cases presenting as nearly as possible identical clinical features, for example the polyarticular symmetrical arthritis of small joints in relatively young subjects in an early stage, and all others rigidly excluded, the results might prove more uniform and it might be possible to associate the type with a definitive infective agent although the way in which infection acts might still be a matter of doubt. As it is, the Streptococcus viridans, the hæmolytic and the anhæmolytic forms all have their supporters with smaller numbers incriminating the staphylococcus and even the Bacillus coli.

Immunological and serological tests appear to incriminate the hæmolytic streptococcus more than the other types both in acute rheumatism and in rheumatoid arthritis. There are, however, many strains of hæmolytic streptococci, the most definitely pathogenic being the A strain of Lancefield, which is regarded as the cause of scarlet fever and it is with this strain that most of the work on immunology has been done. Why should it be the cause of scarlet fever and puerperal fever and at the same time of rheumatoid arthritis? On the face of it it seems unlikely unless there are other potent ætiological factors. It may be that this is the sensitizing agent and some other may act as the direct exciting cause. It would, however, appear essential to define exactly the strain with which the immunological experiments are carried out, and to determine the part played, if any, by the other strains often found in the nasopharynx, B, C, D, F, G and $H$ which, while not markedly pathogenic to man, may perhaps become so in sensitized subjects.

Hæmolytic streptococci are found in the throats of about $20 \%$ of normal subjects and about one-third of these will belong to the A group. Colebrook, Maxted and Johns found hæmolytic streptococci of Group A on the hands of $3.8 \%$ of a series of I8I normal individuals and the Streptococcus viridans in almost every? instance. It is generally admitted that the viridans type is a saprophyte and while it is possible that it may become pathogenic under special conditions this cannot be regarded as proved, but it has been extensively used in the vaccine treatment of arthritis.

The problem is rendered still more puzzling by the work of Zinsser, Hadjopoulos and Burbank and others indicating the possibility of mutation between the various strains and types.

Are we to assume that all these bacteria, and others which might be added, are capable of setting up arthritis without distinguishing characteristics? It would seem probable that the common factor lies in the tissue attacked and not in the strain of attacking organism. The white fibrous tissues are predominantly the seat of attack in rheumatic diseases and a closer study of the pathology of fibrositis, in which biopsy is simple, might throw some light on the problem of arthritis, in one form of which the process may be confined to the connective tissue of the capsule, but, more often originates in the synovial membrane. In fibrositis, nodule formation is a characteristic feature and similarities in the structure of these nodules with the nodes of acute rheumatism and rheumatoid arthritis have been noted. Fisher and others have demonstrated the presence of focal collections of cells, including the giant cells which are met with in Aschoff bodies, and areas of focal hyaline degeneration of connective tissue which would seem to be pathologically similar to the nodules of fibrositis. Stockman described proliferation of the endothelium of the smaller blood vessels in fibrositis and Fisher describes this in the blood vessels of the synovial membrane in arthritis. 
It is generally believed that acute fibrositis is the outcome of the action of toxins and not of bacterial invasion and that such toxins are not limited to those of a specific type of micro-organism but may be chemical as in gout. Bacterial invasion of the joints in arthritis has been found comparatively rarely and such occasional invasion by small numbers has been demonstrated also in controls though rarely. The balance of evidence indicates that the inflammatory symptoms in non-suppurative arthritis, and also in fibrositis, are due to the soluble products of bacterial activity which are probably derived from distant foci and have an affinity for the cells of the connective tissues which react to these foreign proteins in a specific way.

This process is usually termed "Allergy" but since allergy manifests itself in various ways the use of the term in connection with rheumatism is apt to provoke criticism.

The degree of sensitiveness of different tissues varies widely, as Bray points out, and there is a predilection for certain allergens to sensitize certain tissues, each allergen having its favourite point of attack. Rosenow believed that certain strains of streptococci acquired an affinity for the joint tissue if grown under special conditions and he termed these strains arthrotropic. However this may be, it is a reasonable hypothesis not entirely unsupported by evidence that amongst the toxins which may provoke a reaction in fibrous tissue are those of certain streptococci which may be derived from foci in distant parts of the body. These toxins at first sensitize the tissue cells. Subsequently the products of bacterial disintegration set up an inflammatory reaction due to the interaction of the allergen with the sensitized cell, and the pathological changes of acute fibrositis are the result. The cells may be sensitized by the toxins of one strain and the reaction provoked by the products of another which need not be identical but probably is closely allied. Rich has pointed out that in the presence of allergy (specific hypersensitiveness) a harmless protein product of bacterial disintegration is converted into a violent and even lethal poison.

Poynton and Schlesinger have stated that in the more specialized structures such as the joints these reactions to a rheumatic virus lead to secondary changes of degenerative character which probably vary only with the degree of virulence and not with the type of the original infecting agent.

Apart from this acquired sensitivity to bacterial poisons, there is a form of inherited sensitivity to toxins of other kinds, which characterizes such diseases as asthma, and this may be the explanation of hereditary gout. There is in my opinion no doubt that gout, or at least a level of uric acid in the blood higher than the normal, is frequently associated with attacks of fibrositis which may be chronic in onset and course and not acute as in the ordinary manifestations of the disease.

In view of the extraordinary complexity of these problems and the great frequency of the rheumatic diseases, which are an enormous drain on the funds of the Insurance Companies and Approved Societies as well as on the working efficiency of the population, it is remarkable and even deplorable that, among the great number of researches which are subsidized by the various trusts, etc., in this country, investigation into the ætiology and pathology of rheumatic disease so rarely appears. If some of the money, time and intellectual ability devoted to research into diseases and pathological problems, chiefly of interest because of their rarity, could be devoted to this subject, it would be of incalculable advantage to the practice of medicine and the health of the nation. 